\title{
A STUDY OF NUTRIENT DISTRIBUTION IN SEDIMENT LAYER AT SEMBRONG DAM
}

\author{
Abu Talib SH ${ }^{1, *}$, Syed Hashim SIN ${ }^{2}$, and Abustan $M S^{1}$ \\ ${ }^{1}$ Senior Lecturer, Faculty of Civil and Environmental Engineering, UTHM, Johor \\ ${ }^{2}$ Postgraduate Student, Faculty of Civil and Environmental Engineering, UTHM, Johor
}

\begin{abstract}
Reservoir is one of the key sources of water supply as it provides hydroelectric power, domestic usage, agriculture, farming, recreation and provides flood protection. Sedimentation in the reservoir makes the storage of water loss and the sediment sink contain a source of nutrients. Sediment deposition creates habitats for aquatic life but if too much sediment, it can destroy their habitats and even physically alter a waterway. The use of nutrients such as Total Phosphorus (TP) is key to growing plants and animals thus to feed growing populations. An excess of nutrients in the reservoir such as from agricultural activity makes algae growth rapidly and it can affected the water quality in the reservoir. This research was conducted at the Sembrong dam as this dam is a major water source for people in Kluang and parts Batu Pahat and the water quality become decreased because of algae bloom. The main objective of this study is to determine the distribution of nutrient in different location and to determine the nutrient distribution in vertical sediment layer. The study were conducted by taking sediments samples throughout the reservoir by using sediment corer and the sediment have been sliced every $5 \mathrm{~cm}$. The samples were digested using USEPA Method 3050B which is acid digestion for sediments, sludge and soil for TP. The laboratory testing on these nutrients was conducted by following Standard Method for the Examination of Water and Wastewater (APHA, 1999) using spectrophotometer. The highest value of TP obtain is at outlet of the reservoir which is $30.72 \mathrm{mg} / \mathrm{l}$. The results obtained shows that the top of sediment has high number of TP and it decreasing by depth. However, continuous and periodic monitoring should be done to avoid the increasing of the concentration of TP in the sediment to ensure the life of Sembrong dam can be extending for future.
\end{abstract}

\section{Introduction}

The Sembrong dam is a downstream flood protection up to 100 -years and the storage capacity about 18 million $\mathrm{m} 3$ and other function is for water supply. It is big enough to supply drinking water for thousands of people surrounding it. Major water resource for some 120,000 people in the districts of Kluang and parts of Batu Pahat was "slowly dying" due to an algae bloom that cause to decreased the water production and the existence of all marine life in it. Besides, the sediments in the reservoir are also having been shown to exert an important influence on this process.

The sediment is an important part of a lake's ecosystem providing both a sink and a source for nutrients. Sembrong dam surrounding mostly covered by farming, agriculture activities and planting of oil palm trees which means the TP are widely used in fertilizers. Phosphorus and nitrogen are important nutrients that farmer used for the growth of plants in water bodies. With these two nutrients, phosphorus is most often considered to be the nutrients that control the production of algae in water bodies [1]. Furthermore, algae and algal blooms should not be considered as harmful to water quality in a waterway. In fact, algae are an important part of stream and river ecosystems. Algae oxygenate water and convert inorganic matter into organic matter and act as waterway's food chain. With slow moving rivers, the impacts of algae blooms grow rapidly than high stream flow. In fact, nutrients loads from sediment are the primary determinant of algae growth in rivers and the nutrient levels especially TP need to be found. High levels of algae can contribute to eutrophication in rivers and it affected the water supply for people in Batu Pahat and Kluang.

\section{Literature Review}

\subsection{Chemical and Physical Aspects of Lakes}

The most important chemicals in a lake and reservoir are nitrogen and phosphorus. Both chemicals allow the nutrient-rich plants and algae to grow. Besides, other organisms feed off these plants and algae, it creating a complex and healthy ecosystem. The balance nutrients in water may be altered by biological phenomena such as 
"algal bloom" and algae reproduces so rapidly and it prevents any nutrients from reaching below the lake's surface [2]. Sediment is delivered from water erosion that causes the water quality degradation and gets more waterway damages. Most sediment in surface waters derives from the surface erosion and a mineral component involved, arising from the erosion of bedrock and also an organic component arising during soilforming processes [3]. Sediments carried into a reservoir may deposit throughout its full length, thus it can form rising of the bed elevation and may cause of aggradations. The combination of sediment trapping and flow regulation can gives big impacts on the ecology, water transparency, sediment balance and nutrient budget. Besides that, sedimentation can reduce the storage capacity for flow regulation and reduce environmental benefits that depend on releases from storage. Since sedimentation reduces the storage capacity, it also disturbs the flood control benefits, water supply, recreation and hydropower. Reservoir sedimentation is a complex process with varies of the watershed sediment production, rate of transportation, and mode of deposition. Reservoir sediment is depends on the river regime, flood frequencies, reservoir geometry and operation, sediment consolidation, density currents and possible land use changes over the life expectancy of the reservoir. The sedimentation makes the storage of water loss and many types of sediment related problems can also occur to both upstream and downstream of dams [4].

\subsection{Nutrient in Sediment}

Nutrient is an element or compound that important for animal and plant growth. The common nutrients are nitrogen, phosphorus and potassium. Without enough nutrients, they cannot sustain life and if they get in high concentrations, nutrients can be harmful [5]. According to [6], the loss of nitrogen, phosphorus and potassium through application of fertilisers use gives a negative nutrient balance in most soils. There are many sources of nutrients causing eutrophication of lakes and reservoirs. For example, all the activities in the entire drainage area of lake or reservoir that are reflected directly or indirectly in the water quality of water bodies [7]. Direct effect towards water bodies is has high of phytoplankton biomass which means microalgae in suspension in fresh water or marine waters and indirect effect is lack of oxygen in water bodies. These happened when the changes of flora and fauna in the bottom layer [8]. Nutrients enter the aquatic ecosystems through surface area, air or groundwater [9]. Drainage water from agricultural land is contains the phosphorus and nitrogen, usually the amount of nitrogen is higher than phosphorus because phosphorus is usually bound to soil components. The examples of nutrients enter from air is rain water. Rain water contains phosphorus and nitrogen from air pollution, usually nitrogen is over 20 times more concentrated than phosphorus because nitrogen is more freely in the atmosphere than phosphorus [10].

\section{Materials and Methods}

\subsection{Sampling Location}

In this study, sampling locations more focused at 3 parts of the reservoir which is at the inlet of the reservoir, middle of the reservoir and the outlet of the reservoir. Source of water in the Sembrong dam catchment cause of inflows stemming from the major river water flowing which is Sembrong river that flows directly into the dam. However, the presence of this river affects the quality of water in the dam because Sembrong river is covered by agriculture activities, so that the substances or chemical that human used will flow into the water through particles of soil that deposited as sediment into the Sembrong dam. The reason of the sampling taken at three locations mentioned is to achieve the objective which is to understand the nutrient distribution of sediments involved in Sembrong reservoir. The sampling location is divided by three zones and the samples were taken at different checkpoint for each zone in the Sembrong dam.

\subsection{Sampling Method}

The samples were taken carefully and keep safely, ensuring that the sediment will not be affected such as decreasing the volume of sediment besides to avoid the sediment sample mix together. The sediment samples were taken by using gravity corer as shown in Figure 1 and the sample were slicing for every $5 \mathrm{~cm}$. To take the sample of sediment, procedures of the sediment corer need to be following cautiously to ensure the sample is still in good condition for laboratory test. The sample of the sediment with $5 \mathrm{~cm}$ is needed to be taken to the experimental work in the laboratory testing such as TP. The samples need to follow the digestion method before the further testing can be done.

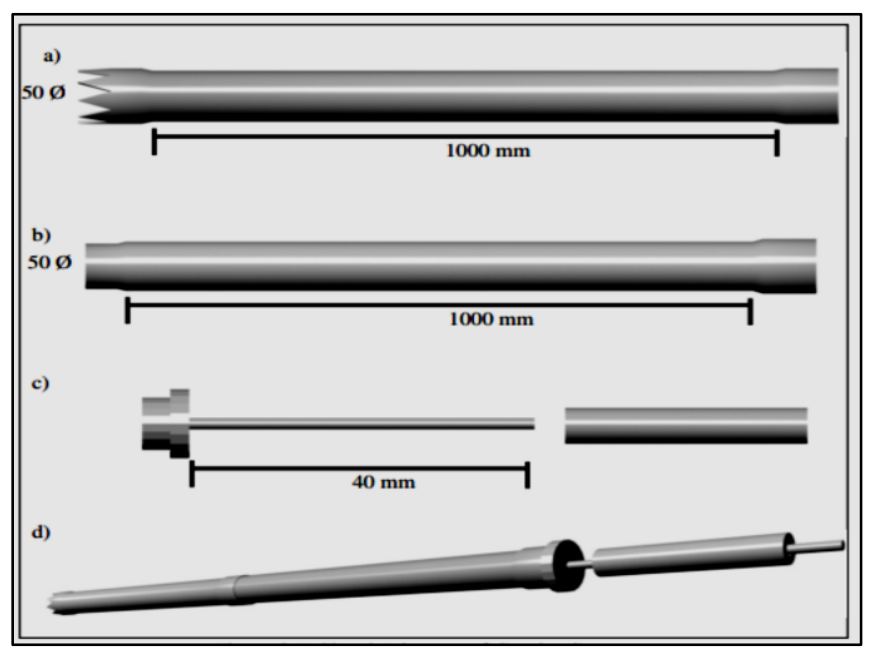

Fig, 1, Sketch diagram of Gravity Corer [11] 


\subsection{Laboratory Testing}

The experiment to the sediment samples was conducted in the laboratory of wastewater laboratory and micropollutant research centre (MPRC), Faculty of Civil and Environmental Engineering, UTHM. The laboratory testing was conducted for digestion and determining the TP. In addition, before doing the test, the sediment samples need to change from solid to liquid by using digestion method. All the experiments will be carried out according to the procedures manual spectrophotometer DR6000 and USEPA method 3050B. Digestion method is using a very strong acid digestion that will dissolve almost all elements that could become environmentally available. For samples of digestion, it is representative 0.5 gram sample is digested with repeated additions of nitric acid (HNO3) and hydrochloric acid (HCL) (USEPA, 1996). For this method of digestion, the experiment will be following the USEPA method 3050B which is acid digestion for sediments, sludge and soil for TP. For determine the amount of TP, the testing that have been conducted is using a reagent tube which is total and acid hydrolysis test vial, $1.54 \mathrm{~N}$ Sodium Hydroxide Standard Solution and PhosVer 3 Reagent. Manual procedures of spectrophotometer DR6000 is a tool that will going to use for determining the TP.

\section{Results and Discussion}

\subsection{Nutrient Distribution in Sembrong Reservoir}

The analysis that have been done in laboratory is TP testing. The laboratory testing was conducted for 6 different locations and each sample that have been sliced for $5 \mathrm{~cm}$. The results of TP was presented in graph and been compared to the previous study which is TP in water. The graph of the comparison is shown in Figure 2 below.

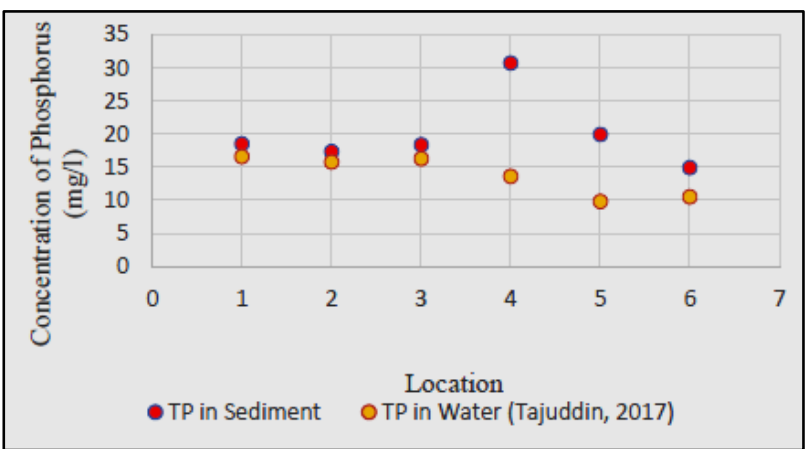

Fig, 2, Total Phosphorus (TP) distributions in water and sediment

From the Figure 2 above, the results of the TP in sediment is higher than the TP in water. The highest value of the concentration of phosphorus is at location 4 which is TP in sediment is $30.72 \mathrm{mg} / \mathrm{l}$ compared to the $\mathrm{TP}$ in water at location 4 is just only $13.6 \mathrm{mg} / \mathrm{l}$. It is quiet big of number of the difference compared to other location. For TP in water, the highest value is at location 1 which is $16.6 \mathrm{mg} / \mathrm{l}$ and the lower TP is at location 5 which is $9.81 \mathrm{mg} / \mathrm{l}$. At Zone I which is location 1 and 2, the TP in water and sediment is almost same amount. This is because at this location, it is nearest to the inlet area which means the nutrient and sediment introduce from the catchment and the flow is starting to reduce and accumulated all the nutrient and sediment. At Zone II, the number of TP in sediment is high which is 30.72 $\mathrm{mg} / \mathrm{l}$ at location 4 . According to the previous study from [11], the location is nearest to the spillway which is outlet of water in Sembrong and at this location it has a highest sediment accumulated at this area. Phosphorus release from sediments can contribute up to $99 \%$ of the TP input in some shallow lakes even there are at the surface sediment [12]. At Zone III which is location 5 and 6, the TP in sediment at location 5 has higher than TP in location 6. As in figure above, the value of TP in sediment and water at location 5 has high difference than location 6. At this zone, the flow almost stagnant in the reservoir. That is the reason of TP in sediment and water at location 6 tend to have low difference than location 5 . The importance of sediments as a potential source of phosphorus has been highlighted in shallow lakes [13].

\subsection{Vertical Distribution of Total Phosphorus Forms in Sediment}

Figure 3 below shows the graph of vertical distribution of Total Phosphorus at Zone I, Zone II and Zone III with different location for each zone. For graph a) which means at Zone I for location 1 (CP1) and location 2 (CP2) shows the concentration of phosphorus versus of sediment depth in Sembrong dam. For location 1, the highest value of phosphorus concentration is $18.51 \mathrm{mg} / \mathrm{l}$ at top of the surface and the value of concentration of phosphorus is decreased by the depth. The lower of the concentration for location 1 is $12.21 \mathrm{mg} / 1$ at depth $30 \mathrm{~cm}$. For location 1, the sediment depth is $30 \mathrm{~cm}$ compared to location 2 with only $25 \mathrm{~cm}$ depth. For location 2, the highest value of the concentration of phosphorus is 17.37 $\mathrm{mg} / \mathrm{l}$ at top of the sediment and the lower of the concentration of phosphorus is $6.63 \mathrm{mg} / 1$ at depth $25 \mathrm{~cm}$. The graph shows the value for both location is decreasing by sediment depth. According to the value from both location, the value TP concentration is highest at top of the sediment as Zone I is near from the inlet of the Sembrong dam. The nutrient content from water flow which is phosphorus comes from the landuse activity at the catchment area. The TP concentration is decreasing by depth as the water flow at the inlet is high and will flushed away the sediment particle to the middle part of the reservoir. As this process repeated, the sediment and it pollutant including nutrient will not retain at the same position. 


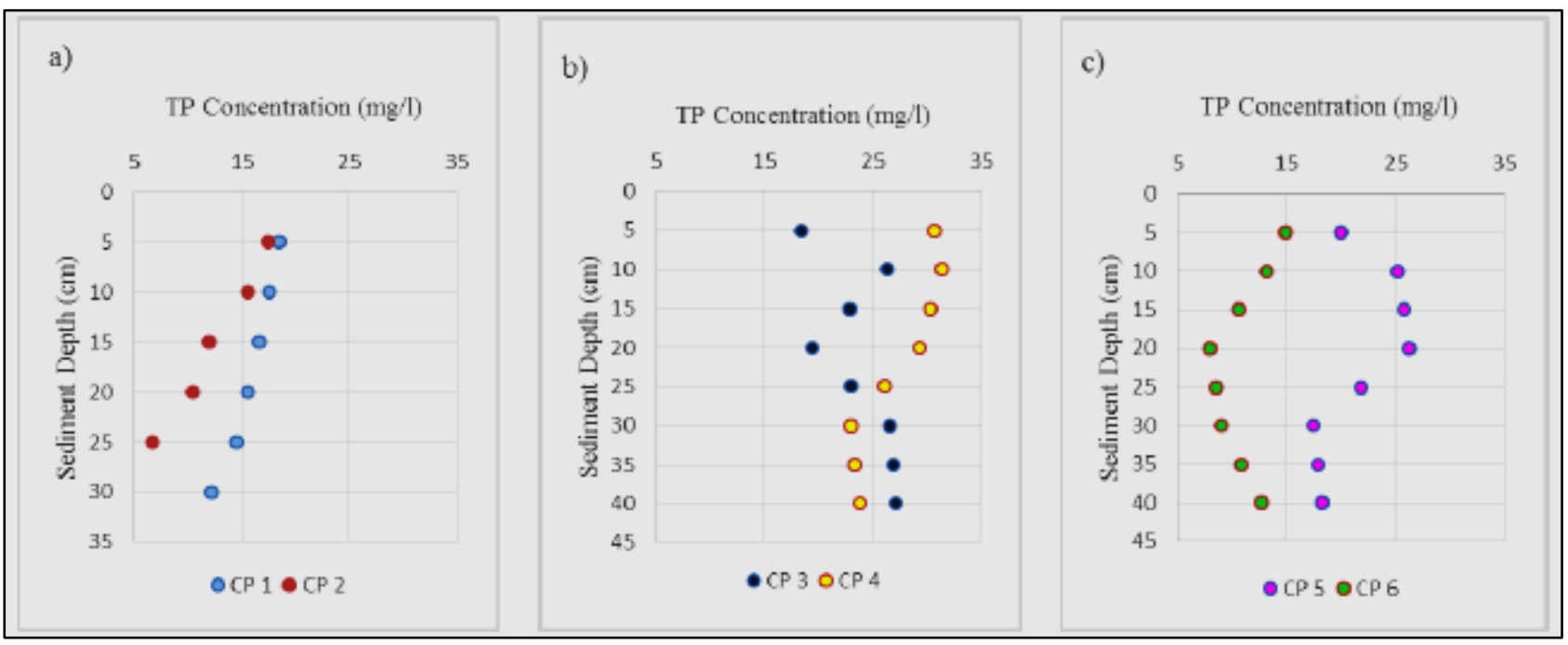

Fig, 3, Vertical Distribution of TP at a) Zone I b) Zone II c) Zone III

From Figure 4.2 b) above which mean for Zone II, the location 3 (CP3) and location 4 (CP4) were conducted in this zone. For location 3, the highest value of concentration of phosphorus is $27.15 \mathrm{mg} / \mathrm{l}$ at bottom of the sediment which is at $40 \mathrm{~cm}$ and the lowest value at location 3 is $18.36 \mathrm{mg} / \mathrm{l}$ at surface or top of the sediment. The value of the concentration of phosphorus at location 3 is lower to higher according to the depth. For location 4 , the highest value of concentration of phosphorus is $31.41 \mathrm{mg} / 1$ at depth $10 \mathrm{~cm}$ from the surface of the sediment in Sembrong dam and the lowest value is at depth $30 \mathrm{~cm}$ which is $22.98 \mathrm{mg} / \mathrm{l}$. The concentration of phosphorus at location 4 according to the depth is higher to lower compared to the location 3 . In addition, location 3 and location 4 have a high value of concentration of phosphorus compared to other location because the location is near to the spillway or outlet in the Sembrong dam. The nutrient from activity surrounding especially phosphorus was flow throughout the reservoir and seep into the sediment due to the low of flow of water because of the distance from inlet and outlet quite distant. Besides that, from Figure $4.2 \mathrm{c}$ ) which mean for Zone III, the location 5 (CP5) and location 6 (CP6) were conducted in this zone. For location 5, the highest value of the concentration of phosphorus is $26.28 \mathrm{mg} / \mathrm{l}$ at depth $20 \mathrm{~cm}$ while the lowest value of concentration of phosphorus is $18.3 \mathrm{mg} / \mathrm{l}$ at depth $40 \mathrm{~cm}$. For this trend of graph as shown in figure above, the concentration value of phosphorus is the lowest and higher at the middle of the sediment depth and lowered at bottom of the sediment. For location 6, the highest value of concentration of phosphorus is $14.94 \mathrm{mg} / \mathrm{l}$ at depth $5 \mathrm{~cm}$ which mean at top of the sediment and the lowest value of concentration of phosphorus is $7.98 \mathrm{mg} / \mathrm{l}$ at depth 20 $\mathrm{cm}$. For this type of graph, the trend of graph of concentration of phosphorus is higher in top, lower at middle and increasing at bottom of the sediment. From trend of graph for location 5 and 6, it is opposite result for both value because at location 5 , at middle sediment depth tend to high to low by sediment depth and location 6 tend to low and higher by sediment depth. For location 6 , the nutrient flow from water and sediment especially phosphorus is from Sungai Merpoh and at this zone, it surrounded by oil palm include dead trees and stump. Overall review about graph of vertical distribution of Total Phosphorus at Zone I, Zone II and Zone III is the value of TP is mostly higher at top of sediment and decreasing by the sediment depth. Zone II has a high number of TP than Zone I and Zone III because of the location is near to the spillway of the reservoir.

\subsection{Sedimentation and Phosphorus Content at Surface of Sembrong Dam}

Based on the Figure 4 below, the Total Phosphorus (TP) is plotted on the map according to the location that have been decided and devided followed by the zone. The different colour of the plotted on the map is according to the results taken from the experiment. The value that has been taken is from concentration of phosphorus at surface or top of the sediment. Based on the map, it shows that the lower of water depth which means the depth of sediment higher has contain a lot of concentration of phosphorus in the sediment. One of the point which is CP4 has a higher number of concentration of phosphorus in sediment at surface and the value is in between $30.0 \mathrm{mg} / 1$ and $31.0 \mathrm{mg} / \mathrm{l}$. Besides that, CP1 and $\mathrm{CP} 3$ has a value of concentration of phosphorus in range between $18.0 \mathrm{mg} / \mathrm{l}$ and $19.0 \mathrm{mg} / \mathrm{l}$.

\footnotetext{
*Corresponding author: hidayaht@uthm.edu.my
} 


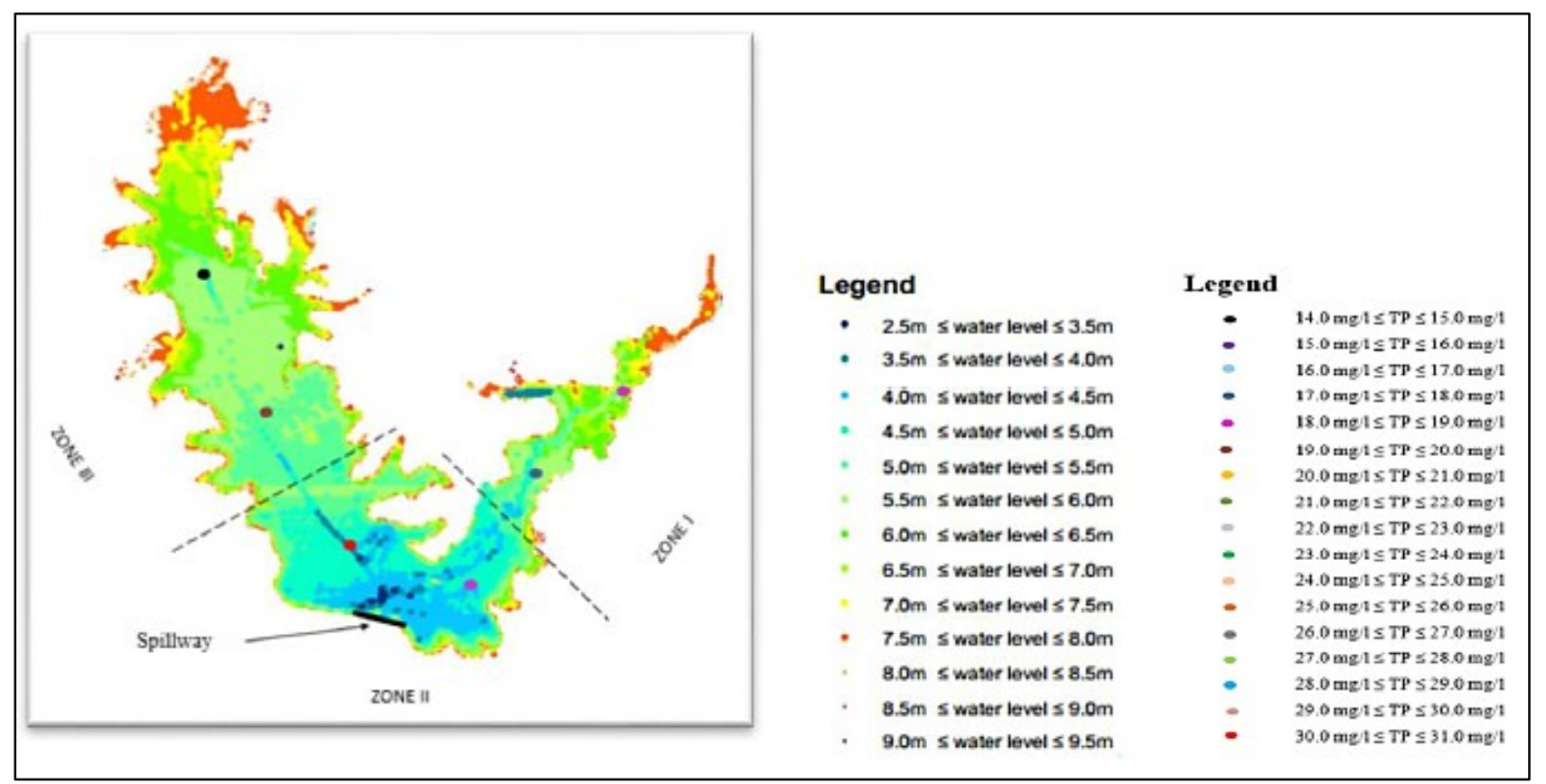

Fig, 4, Map of Sembrong Reservoir based on the Analysis. Edited from [11]

Furthermore, the lowest number of concentration of phosphorus according to the figure above is at Zone III which is CP6 and the the value is in between $14.0 \mathrm{mg} / \mathrm{l}$ to $15.0 \mathrm{mg} / \mathrm{l}$. The reason of the lowest number of concentration of phosphorus at this location because the surrounding area covered by oil palm, stump and dead trees. The phosphorus of this matter is not as high as zone that covered by farming and agriculture activites. Overall review towards map of Sembrong reservoir based on the analysis is at Zone I which is the inlet of the reservoir, it contain lower of sediment depth other than Zone II and Zone III. The sediment depth taken from the Zone $\mathrm{I}$ is only $30 \mathrm{~cm}$ and $25 \mathrm{~cm}$ respectively. Other location the sediment taken is more than $30 \mathrm{~cm}$ which is up to $40 \mathrm{~cm}$. Based on the graph and map plotted, as Zone 1 is the inlet of the reservoir, so that the nutrient content from water flow especially phosphorus that comes from the landuse activity such as farming and agriculture activity was flow into the reservoir. The TP in water and sediment at Zone I is almost same amount because of the sediment and water flow into the reservoir is always change for new particles and new amount of nutrient. The sediment and nutrient content will not retain at the same position as the water flow from inlet and the flow of water is start to reduce and accumulate all the nutrient and sediment into the middle part of the reservoir. As the reservoir of external phosphorus and the source of internal phosphorus, lake sediments play an important role in TP cycling [14].

At the middle part of the Sembrong dam which is in Zone II, it contain the highest value of TP at top of the sediment other than Zone I and Zone III because at this area, the sediment accumulate is higher than other zone. Based on the map, the shallowest part of the reservoir occurs at outlet of reservoir because the sediment and nutrient flow from Zone I has accumulated at this zone. According to [13], TP has been highlighted in shallow lakes. This can proof the result of this study that the shallowest part of water level has high content of TP in sediment. Furthermore, location 5 at Zone III has a high amount of TP in sediment and lower at location 6 . This is because at this zone the flow of water almost stagnant. Location 5 has a high number of TP in sediment because of the sediment at location 4 has a highest number of TP and it flow to the location 5. For location 6, the value of TP in sediment is the lowest TP in sediment among other location because the sediment that accumulates at this location is not change because of the flow is almost stagnant.

\section{Conclusion}

Based on the results, the highest amount of TP in sediment is at Zone II which is at location 4 and the value is $30.72 \mathrm{mg} / \mathrm{l}$. The TP were significantly enriched in the surface sediments and tend to higher in upper layers [13]. According to the map, water level at this zone is the shallowest part other than zone because this area is near to the outlet. As the water flow towards the spillway or outlet of the reservoir, the water velocity has decrease and causing suspended solid deposited and accumulates at this area [4]. For Zone I, the amount of $\mathrm{TP}$ in sediment obviously decreased with depth because the zone is nearest to the inlet of reservoir. As the water and sediment flow, the nutrient is not retaining at the same position and always gets new sediment and nutrient depends on the landuse activity. The TP content was clearly related to the regional distribution. The distribution characteristics of TP forms to the entrance of reservoir were very similar [13]. For Zone III, the

Corresponding author: hidayaht@uthm.edu.my 
amount of TP in sediment is decreasing because of the flow of water is almost stagnant and at location 6 , the amount of TP in sediment is the lowest among other location which is $14.94 \mathrm{mg} / \mathrm{l}$. According to [4], the sediment deposition at this area with no activity along the Merpo river does not affect huge changes of the sediment in the reservoir. As the flow almost stagnant in this area, so that the nutrient content is not flush out or in as much as in Zone II. Determining the nutrient distribution in vertical sediment is also been achieved as the results that has been plotted in Figure 2. The TP in the Sembrong river sediment has been proven by the presence of high value of TP in sediment layer at upper layer and according to [13], the TP is significantly enriched in the surface of the sediments. Mostly the top of the sediment in Sembrong dam which is at surface has high number of TP and it decreasing by depth.

\section{Acknowledgement}

We thank the Batu Pahat Department of Irrigation and Drainage for their hospitality, Universiti Tun Hussein onn for funding this project under the Research University Grant (Geran Penyelidikan Kontrak Khas 2015) vot no. U422 and Research, Innovation, Commercialization, Consultancy Office UTHM (ORICC) for Postgraduate Research Grant (GPPS).

\section{References}

1. D. W. Schindler, Evolution of phosphorus limitation in lakes. Science, 195(4275), 260-262 (1997).

2. K. Rutledge, M. McDaniel, D. Boudreau, T. Ramroop, S. Teng, E. Sprout, H. Costa, H. Hall, $\mathrm{H}$ and J. Hunt, The Encyclopedic Entry Lake. National Geographic (2011).

3. N. Junakova \& M. Balintova. Assessment of nutrient concentration in reservoir bottom sediments. Procedia Engineering, 42, 165-170 (2012).

4. T. Sumi, \& T. Hirose. Accumulation of sediment in reservoirs. Water storage, transport and distribution. UNESCO-IHE and EOLSS Publishers Co. Ltd., Paris, France, 224-252 (2009).

5. L. Gardiner. "Traveling Nitrogen." Windows to the Universe. National Earth Science Teachers Association (2005).

6. R. Gensch. Urine as Liquid Fertilizer in Agricultural Production in the Philippines: A Practical Field Guide. Xavier University Press (2011).

7. W. Rast, \& M. Straš kraba. Lakes and Reservoirs: Similarities, Differences and Importance, Vol 1.United Nations Environment Programme-International Environmental
Technology Centre; International Lake Environment Committe Foundation (2000)..

8. S. H. A. Talib. Sedimentation Modelling and Nutrient Profile in Bukit Merah Reservoir. Universiti Sains Malaysia : Doctor of Philosophy Report (2014).

9. M. Selman, S. Greenhalgh, R. Diaz, \& Z. Sugg. Eutrophication and hypoxia in coastal areas: a global assessment of the state of knowledge. World Resources Institute, 284, 1-6 (2008).

10. W. Rast, \& M. Straš kraba. Lakes and Reservoirs: Similarities, Differences and Importance (Vol. 1). United Nations Environment Programme-International Environmental Technology Centre; International Lake Environment Committe Foundation (2000).

11. M. W. Z. Nasru. Sedimentation assessment in Sembrong Dam, Batu Pahat, Johor. Universiti Tun Hussein Onn Malaysia : Bachelor Degree's Project Report (2017).

12. L. Volterra, M. Boualam, J. P. Duguet, X Bonnefoy, A Ménesguen, and J Duchemin. Eutrophication and Health. Report from European Union and World Health Organization (2002).

13. D. A. Shilla, T. Asaeda, \& M. Kalibbala. Phosphorus Speciation in Myall Lake Sediment, NSW, Australia. Wetlands Ecol Manage, DOI 10.1007/s 11273-008-9087-5 (2008).

14. S. L. Xiang, \& W. B. Zhou. Phosphorus forms and distribution in the sediments of Poyang Lake, China. International Journal of Sediment Research, 26(2), 230-238 (2011).

15. L. Q. Xie, P. Xie, \& H. J. Tang. Enhancement of Dissolved Phosphorus Release from Sediment in Hyper-Eutrophic, Subtropical Chinese Lake. Environmental Pollution, No. 122, pp. 391 - 399 (2003). 